\title{
Research on the Training of Language Service Professionals Based on the School-Enterprise Cooperation
}

\author{
Lihua Sun \\ School of Foreign Languages \\ Northeast Electric Power University \\ Jilin City, Jilin Province, P.R. China, 132012
}

\author{
Zhiyuan Li \\ School of Foreign Languages \\ Northeast Electric Power University \\ Jilin City, Jilin Province, P.R. China, 132012
}

\begin{abstract}
The emergence of language service is the inevitable result of the development of science, technology, and economy in the new era. Compared with the traditional de-contextual language translation teaching, the training of language service professionals is socially oriented and focusing on the needs and services of society. Both competent teachers and effective teaching contents are needed to meet the requirements of the training of language service professionals. Based on the schoolenterprise cooperation, a contextual platform is constructed by a multilevel team of teachers, engineers, and technicians with specific teaching modules for the training of language service professionals. The language services and professional services that were originally separated have also been integrated by the school-enterprise cooperation, and hence met the requirements for the training of language service professionals.
\end{abstract}

Keywords-language service; context; school-enterprise cooperation; course construction scheme

\section{INTRODUCTION}

The promotion of the "Belt and Road" initiative and the deepening of China's economic and cultural "going out" strategy are inseparable from the transformation of language information. Traditional translation services can no longer fully express the contents covered by linguistic information conversion, and cannot meet the needs of society. In such circumstances, language services have increasingly attracted the attention of practitioners and academics in universities. The emergence of language services is the inevitable result of the development of science, technology, and the economy in the new era. It is the adjustment of translation teaching with the changes of the background and market demand. It is also the extension, broadening and development of language translation under the new situation of social demand. Compared with the traditional de-contextual language translation teaching, language services tend to be social-oriented, focusing on needs and services. This highlights the effectiveness of language tools in teaching, i.e. the economic characteristics of language. It has a huge impact on the traditional translation teaching in China. It requires language service professionals not only to have good language competence and cross-cultural communicative competence, but also to possess the specialty of providing industry and technical support with language services ability.

\section{BASIC CONTENTS OF TRAINING OF LANGUAGE SERVICE PROFESSIONALS}

\section{A. The Theoretical Basis of Training of Language Service Professionals}

Functional linguistics theory points out that the object and purpose of language activities are closely related to the specific context and genre [1]. Context refers to the choice of linguistic forms by the occasions, contents and objects on which language activities are carried out, such as the occasions of the press conferences and the signing of the commercial contract. Although English is used in different circumstances, the syntactic structure, formality, and meta-discourse are quite different. Genre refers to the academic or industrial activities in which members of the academic or industrial community abide by the fixed rules of activities, such as case studies, experimental reports, operation manuals, product descriptions and periodical papers, etc., all have the specific discourse tradition [2].

According to contextual theory and genre analysis theory, the theoretical knowledge and research results of any subject or profession are constructed and exchanged through specific linguistic methods. Apart from the common-core grammar and vocabulary, they all have their own unique ways of thinking or research paradigms, and their discourse patterns and linguistic structures are also different. That is to say, texts of different disciplines differ not only in content and knowledge, but also in the way they expound opinions, demonstrate processes, draw conclusions and persuade readers [3]. Even the textual structure, rhetorical devices and syntactic forms of the same genre vary from subject to profession. Therefore, context and genre are the theoretical basis of language services. Without the understanding of the specific context and genre of the profession or industry, it is not known how the specific genre knowledge and achievements of the profession or industry are constructed and communicated by language. Language services are empty talk. Therefore, language services need to train professional language service professionals, who not only have translation skills, but also have professional knowledge and professional language expression ability.

This study is sponsored by Jilin Association for Higher Education (JGJX2019B7) 


\section{B. Social Needs of Language Service Professionals}

According to the survey report of experts and scholars on China's translation service industry, language services involve various fields in politics, economy, culture and so forth, but at the same time language services have the characteristics of highly professional concentration in some industries [4]. Language service professionals are mainly involved in the fields of information and communication, economy, medical treatment, law, science and technology and so on, among which the demand for translation services in manufacturing is the largest [5]. In short, the main content of language service is highly professional. This requires language service professionals, on the one hand, determined by their professional characteristics to have general language ability, on the other hand, determined by their professional characteristics to have professional language ability.

\section{Basic Quality of Language Service Professionals}

Based on the analyses of experts and scholars, the author believes that the basic qualities of language service professionals should include interpersonal communication, team cooperation, professional ethics and norms, and general professional qualities such as multi-task coordination and organizational management, stress resistance, problem solving, team spirit, and more importantly, general professional qualities. Language service professionals should have both language and professional abilities. Such special competence requirements will inevitably challenge language services. From the aspect of practical work, the professional application scenario is extensive and the efficiency requirement is high. It is possible to carry out such work as interpretation and translation, technical writing, and technical communication at anytime and anywhere. Language services should establish effective professional communication in their work and be able to effectively convey professional information in plain and understandable language. From the aspect of language services, the vertical areas of all walks of life are characterized by large professional differentiation, weak versatility and fast updating of professional information. This poses a higher challenge to the professional knowledge ability requirements of language service professionals. It is required that language service professionals have proficient knowledge backgrounds in relevant fields, and at the same time, they need to fully understand the specific professional knowledge, professional jargon and terms.

\section{SCHOOL-ENTERPRISE COOPERATION MECHANISM}

Functional linguistics theory points out that context and genre are the theoretical basis of language services. In language communication activities, context is the premise. Discourse associated with context is found and reasoned according to ostension-inference to set up optimal relevance so as to achieve the purpose of understanding the discourse [6]. The construction of context requires continuous improvement of bilingual competence and expansion of professional knowledge. The richer the accumulation of linguistic competence and professional knowledge, the more accurately the meaning of the source language can be understood. Therefore, the basic context can be formed, and the pressure of short-term preparation can be effectively reduced. Language competence and professional knowledge are the fundamental foundation of context. A series of preparations before the beginning of language service, especially the preparation of professional knowledge background, have become an important prerequisite for the training of language service professionals. Schoolenterprise cooperation provides an effective platform with language and professional knowledge for the training of language service professionals.

\section{A. Contents of School-Enterprise cooperation}

In the Guiding Opinions on the Transition and Development of Local Undergraduate Universities (Draft for Opinions), the Ministry of Education proposed that "the integration of industry and education and the cooperation between universities and enterprises should be the main paths to guide and promote the transformation and development of some local undergraduate universities to applied technical universities through pilot promotion and demonstration guidance, so as to form the integration of industry and education and school-enterprise cooperation [7]." Schoolenterprise cooperation, therefore, is one of the main reform directions of professional personnel training in Schools and universities. School-enterprise cooperation provides a strong guarantee for the practical training of language service professionals.

In the early 20th century, the University of Cincinnati first put forward the concept of "cooperative education". Then more and more scholars and experts devote themselves to the research of school-enterprise cooperation. Experts and scholars have carried out in-depth research on school-enterprise cooperation, and made a detailed discussion on the reasons, significance, objectives, tasks, and cooperation mechanism of school-enterprise cooperation, which has promoted the development and perfection of the concept of school-enterprise cooperation. Domestic research on school-enterprise cooperation began in Higher Vocational Schools at the earliest time. Xuan Liping proposed to build a basic model of deepening school-enterprise cooperation in Applied Undergraduate Schools with three key elements of "personnel training program, practical teaching platform and cultural integration [8]". After years of development and improvement, school-enterprise cooperation mechanism plays a decisive role in higher education.

\section{B. The Target of School-Enterprise Cooperation}

The target of school-enterprise cooperation for the training of language service professionals is to make full use of the teaching resources of university and the practical environment of enterprise. With the ultimate objective of mutual benefit and reciprocity, both the university and enterprise establish the allround and in-depth cooperation, through which the theory and practice are unified effectively. Thus, the specialized language service professionals adapted to the needs of the market are trained.

The objectives constructed for the training of language service professionals should be based on the integration of universities and enterprises. The traditional training objectives should be boldly reformed. On the basis of guaranteeing 
students' solid bilingual knowledge and translation skills, the training of professionalism required by the market should be focused on the needs of enterprises. To fulfill the objective of personnel cultivation in Schools and universities, it is necessary to cooperate with enterprises in depth so as to realize the seamless connection between language service professionals and employers with the requirement of professional characteristics, and hence to serve the social economy.

\section{Significance of School-Enterprise Cooperation}

School-enterprise cooperation provides a professional practice platform for seamless connection between language service talents and employers. Enterprises provide a contextual practice platform of specific industry macro-backgrounds and relevant vertical domain expertise for language service training. Language service professionals obtain precise knowledge of professional background and professional terms, so as to achieve the maximum contextual effect.

School-enterprise cooperation enables language service professionals to improve their professional knowledge in the shortest time, which can shorten the preparation time and improve the work efficiency. Having considerable professional knowledge, language service professionals with the language competence can realize the information and communication intention of language communication activities, i.e., they can use professional terms and jargon to describe professional information more accurately and concisely, and they can also accomplish the task of professional communication smoothly. The fluency guarantees the quality of language service. The professional context provided by school-enterprise cooperation enables language service professionals to understand the knowledge background more macroscopically in the professional field, to build the knowledge framework more precisely, and to extract and utilize professional terms more accurately. The specialization service and language service, which were separated from each other, have been organically integrated, which has effectively improved the efficiency of work, thus meeting the requirements of language service professionals training. The professional services and language services that were originally separated have also been integrated, which has effectively improved the efficiency of work and thus met the requirements for the training of language service professionals.

\section{Course Construction Scheme Based on the School- Enterprise Cooperation}

Linguistic competence and professional knowledge are the foundation for the formation of context. School-enterprise cooperation is the platform for specialization of language services and the provision of effective language and professional knowledge for the training of language service professionals. Since Northeast Electric Power University is a highly professional university of science and engineering, the School of Foreign Languages of the university has established a bridge between students' linguistic competence and professional knowledge through the cooperation with the School of Electric Engineering and Hongshi Power Plant.
Firstly, a multilevel team of teachers has been established through school-enterprise cooperation. In-school teachers "go out" while electrical professional teachers, the engineers and technicians of electric power enterprise "come in", realizing the complementary advantages of in-school and out-of-school teachers.

Teachers of the School of Foreign Languages enter the simulation laboratory of the School of Electric Engineering to grasp the professional knowledge of electric power production, processing, transmission and energy storage. They also regularly visit the workshops of power plant to be familiar with the production environment and processing flow, listen to the explanations of workshop engineers and technicians, and master the working principles of important equipment.

Teachers of the School of Electric Engineering enter the classroom of the School of Foreign Languages; they not only take charge of the teaching of electrical professional knowledge, but also give lectures to provide students with necessary electrical expertise.

Engineers and technicians of Hongshi Power Plant come into the School of Foreign Languages to give lectures on the energy strategy and corporate culture of electric power enterprises, and they also explain the most cutting-edge and practical knowledge of the professional fields in the production configuration, production process and operation of power plants as well. Based on the school-enterprise cooperation, the establishment of the multilevel team of teachers of practical courses reasonably allocated the tasks of engineering and technical personnel in universities and enterprises.

Secondly, the module teaching of language service courses is distributed in turn from teaching, practice to actual application based on the school-enterprise cooperation. Strictly speaking, the platform of school-enterprise cooperation is constructed by language service teaching for students to acquire linguistic competence and professional knowledge and form a specialized context. Through the multilevel teacher team established based on school-enterprise cooperation, students are guided to achieve the goal of language service teaching based on school-enterprise cooperation, in which the practical curriculum of school-enterprise cooperation plays a very important role.

The practical course of school-enterprise cooperation can be divided into three teaching modules: basic training of translation skills; simulation training of translation of electric power projects; practical training of students in power plant, i.e. students visit power plant after the in-school training. The first module solidifies students' translation skills, and teachers refine common mistakes through students' practice and correct them; the second module simulates real translation projects, by which teachers provide students with project cases of power construction engineering or power process and ask students carry out translation training for power construction engineering or power process; and the third module combines school with enterprise. It gives a chance to students to know well the real producing and processing in enterprises.

The modular teaching scheme based on the schoolenterprise cooperation is more comprehensive. Due to the 
advantages of the multilevel team of teachers inside and outside the school, the school-enterprise cooperation makes the teaching content more diversified. Based on the schoolenterprise cooperation, students can be aware of the industrial production and processing environment, greatly improving the actual practicing ability of language services.

Finally, the language service teaching scheme constructed based on the school-enterprise cooperation requires a diversified evaluation system. The final assessment method of students should be combined with three teaching modules, and the teaching in schools and enterprises should be included in the assessment scope. The final assessment results are the sum of examination results, translation project simulation results and enterprise project training results. The assessment methods are more scientific and comprehensive.

The Language Service courses based on the schoolenterprise cooperation can achieve the improvement of students' bilingual ability and the expansion of professional knowledge. The richer the accumulations of language ability and professional knowledge, the more perfect the construction of context.

\section{CONCLUSION}

Compared with the traditional de-contextual language translation teaching, the training of language service professionals is socially oriented and focusing on the needs and services of society. Both competent teachers and effective teaching contents are needed to meet the requirements of the training of language service professionals. It is the adjustment of translation teaching with the changes of the demand of market. It is also the extension, broadening and development of language translation under the new situation of social demand. The demand for such language service professionals has been reflected in the recruitment of language service teams in enterprises.

School-enterprise cooperation is an effective platform for specialization of language services and the provision of language and professional knowledge for the training of language service professionals. Enterprises provide a platform of specific industry macro-backgrounds and relevant vertical domain expertise for the training of language service. The multilevel team of teachers has been established through school-enterprise cooperation. In-school teachers "go out" while electrical professional teachers, the engineers and technicians of enterprise "come in", realizing the complementary advantages of in-school and out-of-school teachers. And the module teaching of language service courses is distributed in turn from teaching, practice to actual application based on the school-enterprise cooperation as well. The platform of school-enterprise cooperation is constructed by language service teaching for students to acquire linguistic competence and professional knowledge and form a specialized context. Language service professionals obtain precise knowledge of professional background and terms, so as to achieve the maximum contextual effect. The professional services and language services that were originally separated have also been integrated, which has effectively improved the efficiency of work and thus met the requirements for the training of language service professionals.

In general, the modular teaching scheme based on the school-enterprise cooperation is more comprehensive. Due to the advantages of the multilevel team of teachers inside and outside the school, the school-enterprise cooperation makes the teaching content more diversified. Based on the schoolenterprise cooperation, students can be aware of the industrial production and processing environment, greatly improving the actual practicing ability of language services.

\section{REFERENCES}

[1] Halliday, M. A. K. Spoken and Written Language[M]. Oxford: Oxford University Press, 1985.

[2] Swales, J. M. Genre Analysis: English in Academic and Research Settings[M]. Cambridge: Cambridge University Press, 1990.

[3] Hyland, K. Specificity revisited: How far should we go now?[J]. English for Specific Purposes, 2002, 43(4):385-395

[4] Yang Ping, Yang Ling, Zhang Wen, et al. China Translation Service Industry Analysis Report 2014[R]. China Translation Research Institute, China Translation Association, China Translation Industry Development Strategy Research Institute, 2014.

[5] Zhao Shiju. Definition and Type of Language Service from the Perspective of Service Content[J]. Journal of Beihua University: Social Sciences Edition, 2013, 13 (3): 4-6.

[6] Qu Weiguo. Also on Relevance Theory[J]. Foreign Language Teaching and Research, 1993 (2): 9-13.

[7] Ministry of Education's Guidance on the Transition and Development of Local Undergraduate Universities [EB/OL]. (2014-04-15) http:www.jstu.edu.cn/s/3/t/51/88/8e/info34958.htm.

[8] Xuan Liping, Song Zuozhong. Reflections on deepening the training of School-Enterprise Cooperation talents in Applied Undergraduate Schools[J]. Journal of Northeast Agricultural University, 2012 (6). 